Pedagogía y Saberes No. 50

Universidad Pedagógica Nacional

Facultad de Educación. 2019. pp. 11-28

\title{
¿Qué es eso que se llama pedagogía?
}

Artículo de investigación

What Is Pedagogy?

O que é entendido por pedagogia?

Mario Díaz Villa*

Para citar este artículo:

Díaz, M. (2019). ¿Qué es eso que se llama pedagogía? Pedagogía y Saberes, 50, 11-28.

* Profesor de la Universidad Santiago de Cali, doctor en sociología de la educación. Investigador del Grupo ciEDus. Correo electrónico: mdiazvilla@gmail.com 


\title{
Resumen
}

Este artículo de investigación desarrolla un enfoque sobre la pedagogía desde una perspectiva sociológica o, preferiblemente, desde una sociología de la pedagogía. Procura abrir un espacio crítico que poco se ha dado alrededor del substratum de la pedagogía, e intenta responder a la pregunta: ¿qué se entiende por lo que se denomina pedagogía? El artículo también hace un breve análisis de cómo muchos de los discursos producidos a lo largo de la historia tienen que ver con la regulación directa o indirecta de la subjetividad, y se han considerado medios de recontextualización de la razón, la conciencia y el conocimiento. En este sentido, se argumenta que para el discurso pedagógico no hay espacio semántico impenetrable. El discurso pedagógico es un principio intrínseco a toda interacción social y es un medio de reproducción de relaciones de poder y principios de control.

\section{Palabras clave}

discurso pedagógico; pedagogía; sociología; poder; control; interacción social

\begin{abstract}
This research article develops an approach to pedagogy from a sociological perspective or, preferably, from a sociology of pedagogy. It aims to create a critical space that has barely existed around the substratum of pedagogy, and tries to answer the question: What is understood by pedagogy? The article also makes a brief analysis of how many of the discourses produced throughout history have to do with the direct or indirect regulation of subjectivity. These discourses have been considered as means of recontextualizing reason, conscience and knowledge. In this sense, it is argued that, for pedagogical discourse, there is no impenetrable semantic space. Pedagogical discourse is an intrinsic principle to all social interaction and is a means of reproducing power relations and control principles.
\end{abstract}

\section{Keywords}

pedagogical discourse; pedagogy; sociology; power; control; social interaction

\section{Resumo}

Este artigo de pesquisa desenvolve uma abordagem sobre a pedagogia desde uma perspectiva sociológica ou, preferivelmente, desde uma sociologia da pedagogia. Procura abrir um espaço crítico pouco frequente ao redor do substratum da pedagogia e tenta responder à questão: o que é entendido por pedagogia? 0 artigo também faz uma breve análise de como muitos dos discursos produzidos ao longo da história têm a ver com a regulação direta ou indireta da subjetividade e são considerados médios de recontextualização da razão, a consciência e o conhecimento. Neste sentido, argumenta-se que para o discurso pedagógico não existe espaço semântico impenetrável. 0 discurso pedagógico é um princípio intrínseco a toda interação social e é um médio de reprodução de relações de poder e princípios de controle.

\section{Palavras-chave}

discurso pedagógico; pedagogia; sociologia; poder; controle; interação social 


\section{Introducción}

$\mathrm{E}$ ste artículo tiene el propósito de desarrollar un enfoque sobre la pedagogía desde una perspectiva sociológica 0 , preferiblemente, desde una sociología de la pedagogía. A diferencia de los análisis de la pedagogía que privilegian los aspectos metodológicos, técnicos y, fundamentalmente, psicológicos, la propuesta de una sociología de la pedagogía es de extrema importancia dado que no solo permite conectar el análisis de los cambios en la cultura y la sociedad con la reproducción de nuevas formas de conciencia e identidad sino, también, develar las paradójicas y arbitrarias realizaciones semánticas de la pedagogía que hoy habitan con los más variados lenguajes en el campo de la educación.

En este sentido, se advierte que el artículo no intenta dar cuenta de la historia ni mucho menos del estado del arte de la pedagogía, o de lo que se ha denominado su campo conceptual. Tampoco tiene el interés de centrarse en unas u otras tendencias pedagógicas, ni de responder preguntas puntuales sobre la infancia, el aprendizaje, la variedad de modelos pedagógicos, o las técnicas, etc. El artículo procura, fundamentalmente, abrir un espacio crítico que poco se ha dado alrededor del substratum de la pedagogía.

El artículo se divide en cinco secciones. En la primera se realiza una presentación general del problema de la pedagogía - la pedagogía como problema-. En la segunda se intenta responder a la pregunta: ¿qué se entiende por lo que se denomina pedagogía? y se la asocia a discursos producidos a lo largo de la historia que tienen que ver con la regulación directa o indirecta de la subjetividad. En la tercera sección se considera el discurso de la pedagogía, o discurso pedagógico como medio de recontextualización de la razón, la conciencia, la subjetividad, y el conocimiento, y se argumenta que para el discurso pedagógico no hay espacio semántico impenetrable. En la cuarta sección se hace referencia a la pedagogía como principio intrínseco a toda interacción social. En la quinta sección se analizan brevemente las relaciones entre pedagogía, poder, control y comunicación. Finalmente, se presentan unas breves conclusiones.

A lo largo de las secciones, el texto plantea una serie de interrogantes que deben ser objeto de diversos análisis, relacionados con la manera como se presenta hoy la pedagogía bajo una pluralidad de formas posibles de tecnologías y sofisticadas técnicas para producir sujetos más eficientes, competentes y reconvertibles, o flexibles. Esto obliga a pensar en el nuevo papel de las tecnologías al servicio de la inte- racción y del descentramiento de las formas clásicas de constitución de la identidad, como consecuencia del surgimiento de nuevas realizaciones de lo que en otro lugar hemos denominado la gramática del discurso pedagógico ${ }^{1}$.

\section{La pedagogía como problema teórico}

La noción de pedagogía está ligada al clima social, cultural y educativo de cada momento histórico, así como a contextos en los que surgen nuevas concepciones y enfoques. Si bien hace parte de los procesos de formación desde la antigüedad, sus mayores desarrollos coinciden con el surgimiento de la modernidad. Hoy se la asocia al apogeo de los discursos "posmodernos" de la educación y a la transformación de las relaciones sociales y, de esta manera, a la constitución de nuevas realizaciones de la subjetividad, la identidad y de las prácticas sociales individuales y colectivas. Así mismo, en las últimas décadas está articulada al apogeo de los nuevos mercados culturales y de las nuevas formas de su producción que han generado una amplia gama de experiencias y diversos tipos y estilos de vida (Rifkin, 2000).

Hoy no podemos hacer abstracción de la noción de pedagogía y, sobre todo, de sus formas de realización en una diversidad de contextos de interacción social, especialmente cuando la transformación de las estructuras y relaciones de las realidades económicas, sociales, políticas y culturales denominadas globales, posfordistas o posmodernas han afectado las relaciones entre y dentro de los sujetos, sus experiencias y sus prácticas. En este sentido, resulta necesario comprender el papel que desempeña la pedagogía en la constitución de los nuevos tipos de relación e identidad sociocultural, educativa, profesional, etc. De allí el reclamo para muchos "expertos" en pedagogía cuando se critica su carácter disciplinario y su tarea reflexiva sobre la educación.

No es fácil para las visiones tradicionales de "lo pedagógico" comprender e interpretar los nuevos sentidos, circunstancias y contingencias, ni las nuevas

1 Este es un punto al cual nos hemos referido en otro lugar. Por el momento diremos que las nuevas tecnologías (de la información y la comunicación) han descentrado no solo las categorías de tiempo, espacio y discurso, sino también los valores de las reglas de la práctica pedagógica. Pero no solo eso, también tenemos descentramientos en la identidad, la interacción y, fundamentalmente, el conocimiento. Este descentramiento se ha producido como efecto de la posible convergencia entre las modalidades pedagógicas flexibles y las nuevas tecnologías. 
relaciones espacio-temporales, y formas de comunicación pedagógica, que redimensionan los significados, sus realizaciones y los contextos donde operan.

Quizás la afirmación precedente sea una apreciación general y descriptiva de algo que requiere un estudio profundo: la manera como la pedagogía ha cambiado radicalmente sus formas de realización a la luz de la influencia del amplio potencial de discursos, prácticas, medios, y nuevos significantes, que hacen parte del arsenal cultural actual, y cobran relevancia y legitimidad a través del significado y del impacto pedagógico que adquieren. Este es un asunto de gran interés si se tiene en cuenta que la pedagogía es un potencial para la identidad, le fija límites, la traza, la centra o la descentra. Podríamos decir que la pedagogía regula regímenes de identidad. También regula regímenes de razón, en tanto que la formaliza y le crea límites con la racionalidad de sus discursos y prácticas. Esto significa que lo razonable no necesariamente depende de la razón, sino de otros factores que no son la razón, tal como lo plantea Horkheimer (2007) en relación, por ejemplo, con "la aceptabilidad de ideales, los criterios para nuestros actos y nuestras convicciones, los principios conductores de la ética y la política, todas nuestras decisiones últimas" (p. 19). En este sentido, podríamos hablar de "lo razonable" (entre comillas) como aquello que depende, no de la razón sino de principios pedagógicos que afectan la razón, fundamentados en las variaciones de la racionalidad moderna o posmoderna. En esto, el maestro tiene un papel determinante.

Hoy cuando todas las tecnologías de todo tipo se han convertido en un gran reservorio de posibilidades pedagógicas que potencian nuevas dimensiones del aprendizaje (desde el know what hasta el know how ${ }^{2}$ necesitamos, más que nunca, comprender el papel de la pedagogía en la constitución de la identidad y en las maneras como posiciona a los sujetos en las relaciones de poder y los principios de control, que subyacen a la forma y contenidos de las diversas prácticas socioculturales.

2 Es importante considerar la hegemonía creciente del know how sobre el know what, que en términos de Lyotard (1987) significa el predominio del saber preformativo en el que "se mezclan las ideas de saber-hacer, de saber-vivir, de saberoír, etc." (p. 18). El know how significa un cambio paradigmático en el lenguaje pedagógico. El énfasis en el know how se refiere, como plantea Lyotard a "unas competencias que [...] comprenden a los criterios de eficiencia (cualificación técnica), de justicia y/o de dicha (sabiduría ética), de belleza sonora, cromática (sensibilidad auditiva, visual), etc., [...] y remite a 'buenas' actuaciones con respecto a varios objetos del discurso: conocer, decidir, valorar, transformar" (Lyotard, 1987, p. 18).
Esto obliga a preguntarnos por la función que tiene la inmensa diversidad de nuevos dispositivos tecnológicos en el conocimiento, el saber y el hacer; en las emociones, en las adhesiones inconscientes, en particular, y en las transformaciones pedagógicas, en general, en una sociedad que ha desarrollado múltiples medios de pedagogización ${ }^{3}$ casi que totales de la vida, la educación y el trabajo ${ }^{4}$. Es conocido que el "optimismo tecnológico" ${ }^{5}$ ha inundado el campo de la educación, en el cual se ha producido una diversidad de entornos virtuales de aprendizaje que han debilitado profundamente las relaciones entre el mundo educativo y el mundo de la vida cotidiana. La invasión de la pedagogización ha estado acompañada de diversos "optimismos" tales como la democratización, la autorregulación, y la transformación y construcción de modalidades individuales del aprendizaje. Por todos los lugares se pregona que el alumno es el centro del aprendizaje, constructor de su propio conocimiento, visible, auténtico, creador y autónomo.

Estos optimismos hacen parte de las características de nuestro tiempo, y de sus procesos sistemáticos de personalización (Lipovetsky, 2002, 2008) en los cuales, inclusive, se ha advertido el carácter "emancipatorio" de las nuevas tecnologías que han obligado a los expertos pedagogos a producir nuevos modelos y modalidades que consideran al aprendiz no solo el centro de gravedad de la práctica pedagógica autónoma sino, también, su protagonista. La pedagogización se ha insertado en todos los procesos de interacción tecnológica, y las tecnologías se presentan como medios pedagógicos de interacción con "otros" virtuales, "anónimos" que se posicionan e intercambian en el gran mercado de la comunicación y la significación ${ }^{6}$. Casi que podríamos argumentar en favor de una ecuación entre tecnologías y peda-

3 Entendemos por pedagogización el proceso de determinación subjetiva que ocurre inconscientemente en los individuos, quienes se identifican e incorporan posiciones y disposiciones que provienen de voces como, por ejemplo, las del mercado. Hábitos, gustos, formas de vestir, hacen parte del consumo inducido que coopta y coarta la identidad y la conciencia. A esto se refiere Bernstein (1998) como identidades de mercado.

4 Al respecto, Cetina y Bruegger (2000) plantean que la manera como las características de la interacción social cambian cuando lo tecnológico se naturaliza y cuando el espacio social es virtual, consensual y alucinatorio, es un problema que requiere numerosos estudios.

5 Como argumenta Lash (2005) "en las formas tecnológicas de vida ya no hay distancia entre el conocimiento y la práctica; el conocimiento ya no reflexiona sobre el hacer; antes bien, el hacer es al mismo tiempo conocer" (p. 45).

6 En este contexto el "otro virtual" se presenta bajo la forma de texto. 
gogía, y de la asimilación de la cultura tecnológica a un nuevo medio de pedagogización. ¿Nos encontramos, entonces, frente a una sociedad totalmente pedagogizada?

A primera vista resultan comunes los nuevos escenarios en los cuales la pedagogización termina siendo una práctica al servicio de la tecnología, y más sorprendente que las tecnologías se posicionen como nuevos dispositivos pedagógicos ${ }^{7}$. ¿Cómo afecta esta relación la naturaleza misma de la pedagogía? ¿Nos encontramos aquí con una crisis del dispositivo pedagógico clásico? ¿Hasta qué punto las tecnologías pueden estar generando efectos contrarios al "optimismo tecnológico" (¿pedagógico?) de las instituciones educativas? ¿Hasta qué punto -y contra toda pedagogía crítica - el énfasis en la pedagogía del "saber hacer", mediado por las tecnologías, y expresada en las denominadas "habilidades", "destrezas" o "competencias", ha inhibido pensar su posible carácter emancipatorio? Pero también, ¿hasta qué punto las tecnologías han introducido nuevas formas de servicio, comunicación y toda clase de procesos y productos educativos que institucionalizan nuevos modelos de vida, que, si bien son relativamente personalizados, pueden considerarse dispositivos de reciclaje de la identidad, dependientes de las nuevas formas de representación dominante de una sociedad cada vez más pedagogizada? En síntesis, ¿hasta qué punto es posible hablar - en este escenario- de una "sociedad totalmente pedagogizada"?

Es evidente que estas preguntas le plantean nuevos problemas al cambio social. Tendríamos que interrogarnos, entonces, el cambio social para qué, para quién, cómo, ¿qué grupos tienen acceso a los procesos y productos del cambio social? y ¿qué grupos quedan marginados de este cambio y de sus sofisticados procesos y productos? Si el acceso a los servicios básicos -incluida la educación- permanece desigualmente distribuido entre los grupos sociales, si las cifras de los organismos nacionales e internacionales muestran avances precarios en materia de acceso, uso y calidad de los servicios, es posible, de igual manera, mostrar el inequitativo acceso a las modernas experiencias culturales, como

7 Los pedagogos defenderían el punto de vista contrario. La discusión sobre este aspecto tiene que ver con la autonomización de los dispositivos tecnológicos, los cuales hoy tienden a considerarse verdaderos dispositivos pedagógicos. Infortunadamente, toda la discusión sobre las tecnologías que median en el campo de la educación tiene un sabor fuertemente instrumental y funcionalista, y poco se ocupa de la posible potencialidad democratizadora, transformadora, y emancipadora de las tecnologías modernas, pero también de su profundo poder alienante. las denomina Rifkin (2000), las cuales permanecen desigualmente distribuidas. Aparentemente, este no es un problema de la pedagogía para expertos, tecnócratas y tecnólogos instrumentalistas del campo quienes piensan, por ejemplo, que la facilitación del aprendizaje es un simple asunto metodológico. La pedagogización parece convivir con el inequitativo acceso a la distribución de los recursos físicos y simbólicos, que hacen colapsar el imaginario de la equidad social, a pesar de su retórica globalizada.

Si bien la cultura, la educación, el trabajo, la ciencia y la tecnología hacen parte de la vida social, no significan lo mismo para, ni hacen parte de la vida de ciertos grupos sociales, los cuales en virtud de sus condiciones de existencia, tienen formas de socialización desprovistas de las herramientas materiales, sociales, intelectuales y socioafectivas. Esta carencia material y simbólica ejerce un impacto negativo sobre las formas y contenidos de los contextos de interacción propicios para el crecimiento intelectual y social de los aprendices, y tiene una relación directa con los medios que selecciona la pedagogía para unos y otros grupos sociales ${ }^{8}$. Unos grupos tienen mayores y mejores formas de acceso a los diversos medios y contextos de pedagogización, ya se trate de contextos de pedagogización formal o informal. Esto hace ampliamente variados sus estilos de aprendizaje, recreación e internalización de nuevos significados. Otros grupos solo tienen un acceso parcial, en muchas ocasiones precario, y si bien están expuestos a los medios y contextos de pedagogización, sus escasas posibilidades de comprensión son motivo de fuertes conflictos sociales, que se expresan en múltiples formas de resistencias no elaboradas.

De allí la importancia de pensar la pedagogía no simplemente como una matriz social, técnicamente analizable, sino como un medio estructurante de límites, posiciones y prácticas desigualmente distribuidas $y$, de esta manera, de identidades, que se producen en contextos de interacción estratificados, ya sea fuera de la escuela o dentro de ella. Más allá

8 Aquí hay que decir con todo el énfasis posible que hay un principio distributivo, no necesariamente intrínseco al dispositivo pedagógico, que afecta la distribución inequitativa del conocimiento, de los recursos (físicos y simbólicos), del acceso y del aprendizaje. Los aspectos remediales de estas distribuciones inequitativas se expresan, ya en las políticas internacionales y nacionales de mejoramiento de una educación que no mejora, ya de manera perversa en las ayudas filantrópicas que recaban recursos fuera de servicio - computadores obsoletos, por ejemplo- para suplir las carencias de aquellas escuelas que tienen una muy pobre existencia de recursos o que no alcanzan a acceder a la escasa asignación presupuestal que otorga el Estado. Existen otras formas filantrópicas que terminan siendo, por demás folclóricas. 
de preguntas como ¿qué es el aprendizaje?, ¿cómo aprenden los niños? o, ¿cómo aprender o enseñar mejor? que, evidentemente, son importantes, pero que se centran en la instrumentalidad cognitiva, se requiere comprender el papel de la pedagogización de formas de ser, saber o hacer, y el de la cultura en la legitimación de los principios culturales dominantes dentro de y entre los grupos sociales ${ }^{9}$. Esto necesariamente implica pensar relacionalmente la pedagogía y apuntar a aquellas categorías externas que inciden en sus discursos y prácticas como, por ejemplo, el lenguaje, la economía y sus efectos; las tecnologías, la globalización, las relaciones de clase, el poder, el control, junto con las representaciones que construimos a partir de las posiciones hegemónicas presentes en todas las épocas y en todos los escenarios sociales.

También es necesario comprender las formas de inclusión o exclusión de las que son portadoras las modalidades pedagógicas. Esto requiere el examen tanto del mecanismo interno de la pedagogía como de la funcionalidad de este en contextos mediados por voces y mensajes, en los cuales cada espacio de interacción pedagógica conlleva diferentes formas de experiencia y práctica de los actores socializantes y socializados con un determinado capital cultural que, expuesto en o a la interacción regula, a su vez, su experiencia social ${ }^{10}$.

9 El énfasis creciente en la eficiencia interna de la pedagogía es lo que ha hecho que cada día se preste más atención a aspectos instrumentales como la existencia de recursos, el tiempo dedicado al aprendizaje, su gestión, el seguimiento a los estudiantes, su evaluación, los espacios de aprendizaje, etc. Todos estos aspectos hacen parte de lo que podríamos llamar una economía política de la pedagogía que, en tiempos de la globalización, pretende gerenciar de manera totalizante los procesos de interacción social, afectando evidentemente las disposiciones de los aprendices. Por esto, independientemente de sus realizaciones particulares, hay en las pedagogías modernas una estandarización del aprendizaje que combina la paradigmatización o parametrización de perspectivas pedagógicas flexibles (el constructivismo, por ejemplo) con las necesidades crecientes de actuación autónoma, o flexible, en los escenarios laborales. A esto hay que agregar la estandarización de los procesos tecnológicos cuyos más recientes desarrollos han dislocado las formas tradicionales de interacción social.

10 Es conveniente establecer una diferencia descriptiva entre el capital cultural que aporta el socializante primario y el socializante escolar, y el capital cultural que aporta el socializado. De cierta manera, estas dos formas de capital tienen una relación directa con el principio distributivo cuya realización diferencial tiene serias consecuencias para el ordenamiento de las jerarquías sociales. El problema mayúsculo es que en sí mismo el principio distributivo no tiene voz propia. En términos gruesos, esto significa que la pedagogía en sí misma no es responsable de la distribución desigual. Las responsables son las voces que están detrás de ella. Este es un asunto realmente paradójico.
Explorar la transmisión cultural es explorar la pedagogía, es explorar el posicionamiento de individuos y grupos sociales en discursos y prácticas dominantes y en modalidades de control; es indagar cómo a través de estas prácticas y de sus formas y lenguajes intrínsecos se transmiten modelos de vida, se aprende a actuar como miembro de un grupo social, se adoptan modos de pensar y se internalizan competencias, creencias, conductas, maneras y valores, que constituyen el substratum de la identidad.

Ahora bien, dado que la forma y función del lenguaje no solo se relacionan dialécticamente entre sí, sino también con la estructura social, el estudio de la pedagogía y, en el siglo XXI de la flexibilidad pedagógica, debe considerar el análisis de la relación entre los principios de comunicación y los diferentes contextos socializantes en los cuales los aprendices adquieren imágenes de conducta, carácter y maneras transmitidas por sus diferentes agentes socializantes (pedagogizantes), e internalizan un orden moral, unas formas de relación, jerarquía y autoridad determinantes para su vida educativa y social. Este aspecto es de vital importancia si se asume que existe una relación estrecha entre las modalidades de práctica pedagógica, las oportunidades de aprendizaje, el desarrollo de lo que podríamos llamar el sistema cognitivo de los educandos y la consecuente internalización de formas específicas de identidad.

\section{¿Qué es eso que se llama pedagogía?}

La amplitud de los discursos sobre los cuales se basan los diferentes enfoques de la pedagogía limita su capacidad descriptiva y explicativa, de tal forma que resulta difícil develar tanto su estructura como su semántica debido a sus diferentes objetos de estudio y a la diversidad de sus métodos de trabajo. Es por esto que, como hemos dicho, este artículo presta atención a un asunto fundamental que interesa a las ciencias sociales: por una parte, pensar la naturaleza de la pedagogía como dispositivo transhistórico, y como gramática semiótica que está estructurada por reglas (de distribución, de recontextualización y de evaluación). Por la otra, establecer su papel en la constitución de un determinado tipo de conciencia e identidad en la interacción social, a partir de la determinación de límites físicos y simbólicos que reproduce, y que se internalizan como marcas que se cierran y se abren en la modelación del sujeto.

Lo que sabemos de la pedagogía lo hemos aprendido de un cúmulo indefinido de autores de diferentes épocas, quienes a partir de diferentes campos - 
filosófico, psicológico, antropológico, sociológico-y de diferentes posturas ideológicas -éticas, estéticas, políticas, religiosas - han formulado principios, conceptos, métodos, procedimientos y técnicas, sobre sus objetos de reflexión e intervención que, ciertamente, son numerosos: el niño, el aprendizaje, la enseñanza, el maestro, la escuela, el saber, el texto pedagógico, el contexto, la formación, etc. Unas veces se ha tomado un objeto aislado - el niño, por ejemplo-. Otras veces se han estudiado oposiciones paradigmáticas -enseñanza/aprendizaje, maestro/ alumno- - Sin embargo, la dedicación al estudio de los aspectos metodológicos, técnicos o instrumentales de la pedagogía ha sido inmensa, y se ha prestado poco interés a su papel de dispositivo socializante, a la orientación de los significados que a través de ella se constituyen, a las consecuencias de las diferencias en sus realizaciones contextuales concretas y a sus efectos socioculturales, ideológicos y políticos.

En adición a esto, existe una proliferación de enfoques problemáticos dada su desigualdad descriptiva y analítica, y la exclusión mutua de sus conceptos y métodos. Cada autor, a su modo, ha coadyuvado a configurar el campo discursivo de la pedagogía como un campo heterogéneo, por no decir heteróclito, de límites inciertos, en el cual circulan desde las posiciones ortodoxas, carismáticas y autoritarias, hasta las consideraciones permisivas, personalizadas, plenas de criterios plurales que exaltan la autonomía y la libre realización del sujeto. Unas y otras pueden considerarse conceptualizaciones y recontextualizaciones con diversos grados de rigor que entran a formar parte de las denominadas "teorías pedagógicas" (p. 87) ${ }^{11}$. A esto se agrega la multiplicidad de acciones discretas y singulares que configuran las denominadas "prácticas pedagógicas" que hoy funcionan por la vía de la construcción, la producción, la creación y

11 Por ejemplo, Theodor Geiger (1930), considerado el padre de la sociología de la educación en Alemania, plantea, en su primer programa de sociología de la educación lo que podría ser el quehacer del pedagogo a diferencia del sociólogo: "El planteamiento de cuestiones del sociólogo es teórico. Se interesa por la índole condicionada de los actos educativos respecto de las formas sociales mediante los diferentes sentidos que se supone a aquellos. El pedagogo se preguntaría de un modo distinto si establece el vínculo de una determinada acción con su acto pedagógico, si hay alguna posibilidad, mediante la ejecución del acto en una determinada forma social, esto es, mediante el establecimiento de una determinada relación, de facilitar la consecución de una intención educativa particular [...] el pedagogo se pregunta si se coloca a una determinada distancia propia de una relación de dominio, de camaradería, de frialdad o de cualquier otro tipo; o si tiene que tratar a la mayoría de los pupilos como un grupo solidario o como un agregado de individuos". la innovación, que coexisten con las prácticas pedagógicas coercitivas, normativas, disciplinarias y, hoy, de control.

Así mismo, cada época ha definido las constantes teóricas y metodológicas que le han dado forma al concepto de pedagogía y, en cierta manera, han contribuido a configurar su identidad ontológica como conjunto de normas, prácticas, saberes, valores, etc., pero también como conjunto de reflexiones que se estructuran como un discurso que epistemológicamente no parece tener identidad, a pesar del esfuerzo por definir su singularidad disciplinaria ${ }^{12}$.

Es por esto que en la denominada historia del pensamiento encontramos diferentes discursos que pueden considerarse fuerzas pedagogizantes, "espirituales" o culturales, las cuales han producido, de manera directa o indirecta, principios pedagógicos que aún hoy se presentan como paradigmáticos, aunque no necesariamente pueden definirse como pedagogía pura ${ }^{13}$. Estos discursos, diferentes en su forma y dispersos en el tiempo (Foucault, 1970), constituyen un conjunto de voces convergentes que han tenido un cierto sentido normativo en relación con la constitución de la naturaleza humana, las formas de conocer, la acción e interacción social y sus límites físicos y simbólicos ${ }^{14}$. De la misma manera pueden considerarse principios pedagógicos, independientemente de que sus objetos de conocimiento sean diferentes. Así, por ejemplo, la filosofía, la psicología, la ética, o la estética, la política, sin pretenderlo, pueden considerarse discursos pedagógicos que producen un determinado orden (junto con las posibilidades del desorden, en términos de resistencia, oposición, conflicto) ${ }^{15}$ en el ser, la conciencia, las formas de

12 Uno de los problemas que enfrenta esta reflexión es la poca capacidad crítica sobre la supuesta cientificidad de la pedagogía y su existencia como disciplina singular con una identidad epistemológica. En este sentido, no es mi interés discutir si la pedagogía ha sido o no edificada como disciplina. Ya en mi artículo publicado en 1993 planteé mis críticas a esta postura.

13 Debo aclarar que no es mi interés remontarme a los orígenes de la pedagogía. Este se centra fundamentalmente en ejemplificar con un conjunto de posturas de diferentes campos.

14 Apelando a Foucault, podríamos decir que estudiar la pedagogía es estudiar discursos y prácticas de poder, regímenes de verdad, procesos de normalización y formas de sujeción, asociadas ya a la regulación y a la autorregulación de los sujetos.

15 El orden interno que produce el discurso pedagógico está ligado a la "modificabilidad" que constituye una característica fundamental del sujeto. La modificabilidad es un concepto planteado por Cassirer, para explicar la formación y transformación de las formas orgánicas, esto es, la relación entre movimiento y quietud, entre formas y metamorfosis. Cassirer argumenta que tanto en la naturaleza como en la cultura hay movilidad y estabilidad, pero que ambos factores 
conocimiento, la sociedad, la vida, la moral, a través de sus categorías, juicios, doctrinas, métodos y lógicas discursivas. Ya se trate de lo "físico", de lo "espiritual" o de lo "social", estos discursos, institucionalizados como hechos sociales, han definido de manera directa o indirecta todo aquello que tiene que ver con el "ser" y el "deber ser" del hombre, cuya forma y contenido ha estado atada a supuestos históricamente dominantes (Dilthey, 1988), cuya pretendida validez se legitima pedagógicamente ${ }^{16}$.

El trabajo sobre el deber ser del hombre y sobre las formas que lo procuran, ha estado representado en todas las maneras posibles del pensamiento de cada época. En los diálogos platónicos, por ejemplo, se encuentran "principios arqueológicos" del discurso pedagógico (discurso regulativo) para dar al cuerpo y al alma toda la belleza y toda la perfección posible ${ }^{17}$. Esto se expresa en el concepto de areté que concentra el ideal del proceso educativo del pueblo griego, el cual se consideraba un proceso de construcción consciente: "constituido convenientemente y sin falta, en manos, pies y espíritu" (Jaeger, 2004, p. $11)^{18}$, o en el principio socrático del dominio moral

tienen diferentes expresiones en el mundo de la naturaleza y en el mundo de los hombres (de la cultura). Por esta razón, toda pedagogización, que conduce a la exposición en un orden puede conducir a la ambivalencia y a la resistencia y a la modificación a través de la acción. La puesta en orden no equivale a la asignación de una esencia inmutable en el sujeto: "lo que los individuos sienten, quieren, piensan no queda encerrado dentro de ellos mismos" (Cassirer, s. f., p. 22).

16 También podríamos conjeturar que el espíritu metodológico de la ciencia (Gadamer, 2007) es un principio pedagógico, que modela en profundidad formas dominantes de conocer. No es gratuito, entonces, que aún hoy al lado de las formas más sofisticadas de producción del conocimiento persista el carácter empíricamente unificado de nuestro conocimiento de lo real (Bachelard, 1973). Esto que aparece como un principio epistemológico, se ha comportado históricamente como un principio pedagógico dominante, que ha conducido, como plantea Bachelard, a la elementarización de la ciencia, a la ciencia fácil, a la ciencia de memoria, y con esto, a la tranquilidad que produce la ciencia de lo concreto.

17 Los diálogos platónicos pueden considerarse un discurso pedagógico. Entre estos, "el Protágoras ofrece las diferencias entre el método expositivo, verbalista, propio de este sofista y el método dialógico, heurístico de Sócrates, articulado a través de preguntas y respuestas". Véase el estudio preliminar de los Diálogos de Platón, realizado por Francisco Larroyo. Se toma como referencia la séptima edición, publicada por Porrúa, en 1968.

18 Jaeger (2004) considera que "solo a este tipo de educación puede aplicarse propiamente la palabra formación, tal como la usó Platón por primera vez, en sentido metafórico aplicándola a la acción educadora" y agrega que la palabra alemana bildung (formación, configuración) designa del modo más intuitivo la esencia de la educación en el sentido griego y platónico (p. 13). de sí mismo. La paideia se asocia, entonces, a la forma interior de vida del ser, a su existencia espiritual y a su cultura (Jaeger, 2004, p. 451).

También se recurre a estrategias como la música y la gimnasia para "templar el carácter de los jóvenes": la música como principio regulativo del interior (el alma) y la gimnasia como principio regulativo del exterior (el cuerpo) (Jaeger, 2004, pp. 648 y ss.) ${ }^{19}$.

En la Edad Media el discurso pedagógico tiene como único referente a la iglesia que, como aparato pedagógico, era la base social de la conciencia que se constituye en la $\mathrm{fe}^{20}$. Este discurso mantiene una reciprocidad con la modernidad, al hacer parte de esta como un excedente histórico que tiene expresiones innovadoras del ideal ascético tradicional. Con esto quiero decir que la Edad Media aún habita entre nosotros bajo nuevas expresiones semióticas. ¿Por qué? Porque el discurso pedagógico tiene una especie de singularidad histórica como medio de regulación de la distribución de las visiones del mundo. En este sentido, tiene una vigencia transhistórica, pues incluye lo retrospectivo, en lo presente y en lo prospectivo ${ }^{21}$. Es de esta manera como, por ejemplo, el esencialismo y el nominalismo se reproducen y transmiten bajo las formas más modernas de pedagogía. Esto se puede observar en la forma como la regulación teológica de la conciencia - que es en última instancia, una regulación pedagógica- permanece aún en las visiones posmodernas del mundo. Bernstein (1998) describe tal situación como el silencio triunfante de la voz del discurso pedagógico, en la medida en que nos movemos de una sociedad a otra. Desde su punto de vista, la primera pedagogización total tuvo lugar en la Edad Media en la cual la coordinación de significados, actividades y prácticas estuvo a cargo de la Iglesia católica con "una división simple del trabajo de control simbólico pero persuasivo en sus funciones, y la realización de un mundo completamente coherente y del lugar, posición y función dentro de él" (Bernstein, 2001, p. 365).

19 Véase también, La República. En ella, Platón concibe la música y la gimnasia como una unidad orgánica que da forma al alma y al cuerpo. Esto mismo acontece en La Politica de Aristóteles.

20 Según Paul Vignaux (1954), "la Edad Media trata al hombre en función de Dios, de quien le cree imagen: a las teorías de la Trinidad, corresponden psicologías trinitarias" (p. 14). Con esta fórmula se construye una racionalidad que "pone como punto de partida el texto sagrado, la autoridad divina [...] la tarea de la razón consiste en comprender una revelación" (Vignaux, 1954, p. 16). En la Edad Media la música también tiene un papel importante como instrumento de educación religiosa y de comunicación con Dios.

21 También puede decirse que está incluido en lo retrospectivo, en lo presente y en lo prospectivo. 
La regulación teológica se ha recontextualizado contemporáneamente en una pluralidad de imaginarios libertarios que oscilan entre la afirmación de la autonomía y el conjuro de los males físicos y los males "espirituales" (Lipovetsky, 2002). Las famosas terapias $p s i$ de las que habla Lipovetsky, o la libre elección de cultos religiosos, son ejemplos de la flexibilización de los controles que operan como relajantes del ethos, la identidad y la conciencia. Esta borrasca modernizadora que suscribe nuevas realizaciones pedagógicas es una manifestación de la dimensión histórica generativa de formas de cultura, relación social, experiencia y subjetividad, propia del discurso pedagógico. Dicha borrasca modernizadora tiene pretensiones totalizantes a través de las más sofisticadas tecnologías de control, las cuales permiten asumir desde diferentes discursos que nos encontramos frente a un proyecto de pedagogización total de la sociedad ${ }^{22}$.

En el siglo XVII, dice Cassirer, el triunfo de la filosofía cartesiana cambia por completo toda la imagen del mundo. Cassirer agrega que el siglo XVIII resuelve el problema fundamental del método de la filosofía "no ya volviendo al discurso del método, sino, más bien a las 'regulae philosopahandi' de Newton [...] los fenómenos son lo dado y los principios lo inquirido" (Cassirer, 1972, pp. 21-22). Es a partir de Newton que "la lógica de los hechos" se impone como un paradigma de pensamiento que termina constituyéndose en un recurso pedagógico fundamental, aun hoy, en relación con la forma de acceder al conocimiento. "El camino nos lleva, por lo tanto, no de los conceptos y principios a los fenómenos, sino al revés. La observación es el datum, lo dado, el dato; el principio y la ley el quaesitum, lo buscado" (Cassirer, 1972, p. 23). Esta nueva jerarquía metódica, como la denomina Cassirer, es la que ha dominado el pensamiento occidental desde el siglo XVIII, fundamentado en las concepciones nominalistas y realistas de objetividad, racionalidad, pragmatismo y ciencia. Dichas concepciones no son gratuitas. Ellas forman parte de los procesos de constitución de formas de "conocimiento", "identidad", "conciencia", relativamente domésticas en las políticas del deber ser de la educación, cuyo imperativo básico es movilizar recursos discursivos

22 Aquí propongo una diferencia fundamental entre "pedagogización total de la sociedad" y "sociedad totalmente pedagogizada". Si bien Bernstein postula el segundo concepto, el primero implica la apertura de la potencialidad y las posibilidades que quedan para la resistencia a la totalización, totalización que podría entenderse de manera más cruda como totalitarismo pedagógico de la diversidad de medios y artefactos (tecnologías de la información y la comunicación en sus diferentes dimensiones) pedagogizantes. de diferentes fuentes en función de las tareas de conducción, orientación, control, producción y posicionamiento de los sujetos en principios de orden, relación e identidad (Bernstein, 1998).

Si la filosofía y las ciencias han dividido al ser humano para su estudio, la pedagogía ha retomado desde la antigüedad todo aquello que hace parte de esta división con propósitos formativos interesados. En virtud de su carácter mediador, reproduce límites disciplinarios y controles que tienden a generar en los cuerpos y en las conciencias el sentido de los límites y las limitaciones, o el sentido de las modelaciones y remodelaciones, que van desde la reproducción disciplinaria hasta la incorporación personalizada del control. En esto radica la universalidad de la pedagogía, considerada inicialmente en las universidades alemanas a finales del siglo XVIII, y legitimada como disciplina académica en la segunda década del siglo xx cuando comenzó a estudiarse como cátedra.

Al lado de la filosofía y las ciencias, también, el lenguaje, el mito, la religión, la política y las tecnologías operan como principios estructurantes. El lenguaje es, en primera instancia, una fuente de orden interno y de ordenamiento del mundo. A través del lenguaje se conoce y reconoce el orden de la cultura y sus modalidades de acción e interacción. El proceso de aprendizaje del lenguaje, que parece ser un proceso natural y difuso, constituye un principio regulativo de ordenamiento interior de los individuos. En este proceso, que es una función de la interacción, se puede distinguir la relación activa que el sujeto establece con el lenguaje y con el otro, y la relación pedagógica que el otro - el socializante- establece con el aprendiz. Hay en esta relación un "poder pedagógico" que subyace al discurso, una forma de gobierno, un régimen sobre los sentimientos, ideas, actos, que se refuerzan por el principio pedagógico de la costumbre, esa "atmósfera invariable en la que el hombre vive y existe" (Cassirer, 1951, p. 8), y de la cual no puede sustraerse "como no puede sustraerse al aire que respira" (p. 8).

El mito, la religión, la política y las tecnologías, como formas simbólicas, también participan, a su manera, directa o indirectamente en la construcción de la realidad interior del sujeto y en la construcción de su capital identitario. Esta realidad se va entretejiendo en la interacción social, en la cual el sujeto debe ocupar una diversidad de posiciones que subyacen a sus experiencias cotidianas: "Un sujeto construido en el punto de intersección de una multitud de posiciones [...] entre las que no existe una relación apriorística ni necesaria, y cuya articulación es el resultado de prácticas hegemónicas" (Mouffe, 1994, 
p. 85). Las prácticas hegemónicas se componen de unidades discretas que, si bien conservan su particular expresión histórica, son portadoras transversales tanto de principios de homogeneización como de principios de selección y distribución de individuos y grupos $^{23}$. Es el caso de la religión la cual, según Adela Cortina (1995) ha prestado sus servicios

no solo a la moral, sino también al derecho y al orden político [...] pero también a las sociedades, porque crear vínculos desde la cosmovisión y las creencias compartidas, proporcionar identidad y sentido a sus miembros desde ellas, ha sido desde la antigüedad tarea de la religión. (pp. 15-16).

Pensemos igualmente en los denominados principios de la moral. Independientemente de sus variaciones expresivas (formas expresivas), sus consideraciones históricas han estado vinculadas al discurso y a las prácticas regulativas. El planteamiento según el cual el fin de la moral es el deber y la constitución de hábitos es aún un planteamiento fundamental para dar forma a la conciencia y a la identidad. La moral se acepta como un todo integrado de valores que están en la base del discurso regulativo, discurso que no solo actúa sobre el cuerpo en el que se inscriben las invisibles marcas disciplinarias, sino que también impone límites - controles-que se asumen como marcas espirituales diferenciales y diferentes de conformidad con la diferenciación de los valores reproducidos. El poder pedagogizante de la moral está asociado a relaciones de dominación: [...] ritualiza, impone obligaciones, constituye procedimientos, establece marcas y graba recuerdos [...] en los cuerpos (Foucault, 2004, p. 5) ${ }^{24}$.

Hoy podríamos decir que en todas las épocas la fuerza pedagogizante de la moral y la fuerza moralizante de la pedagogía han caracterizado el vínculo social. La estructura y forma de la moral viaja en el tiempo adoptando diferentes representaciones que van de lo social a lo individual, y de lo individual a lo social. De allí que, por ejemplo, haya un paso entre los adjetivos que nos presenta Hume en 1741 al tratar de la benevolencia (sociable, de buen corazón, humano, agradecido, amistoso, generoso, benéfico)

23 Un ejemplo de la homogeneización lo encontramos en la articulación entre la formación lingüística y la formación religiosa en la familia, donde los principios religiosos comienzan a ser parte de la identidad del socializado, a través del verbalismo cotidiano que sobrepone a la experiencia lingüística la experiencia religiosa.

$24 \mathrm{Al}$ respecto, Foucault retomando a Nietzsche plantea que "el cuerpo está aprisionado en una serie de regímenes que lo atraviesan". Véase Foucault (2004). y los que hoy se reproducen en la familia o en la escuela: "Son conocidos en todos los lenguajes y expresan universalmente el más alto mérito que la humana naturaleza puede alcanzar" (Hume, 1990, p. $30)^{25}$. Esto no significa que pensemos en una moral inmóvil, suprahistórica. La moral como cualquier dispositivo pedagógico varía de conformidad con la transformación de las bases sociales, sin que se deconstruya su papel mediador, entre las fuerzas hegemónicas sociales y políticas y las prácticas individuales, dotadas de una supuesta privacidad que hoy inicia su colapso. Es así como, por ejemplo, si bien en la Edad Media la moral estaba asociada a Dios, su principio y fin, en la modernidad - y posmodernidad- el proceso de la secularización híbrida de su fundamento religioso con el laico, ha debilitado los límites entre el ideal del "deber-ser" y la realización hedónica de este, que menoscaban la base social de los intereses individuales y colectivos. Sin embargo, la fuerza invisible de la moral se impone por encima de la legitimación de la autonomía, como razón para el deber del ser, presupuesto en los valores éticos que subyacen a todos los dispositivos de control. Como plantea Lipovetsky (2008) "la sustitución de un fundamento teológico por un fundamento laico no ha bastado, ni mucho menos, para aligerar a la moral de cualquier carácter religioso" (p. 35). Esto es válido para el "deber" moderno y aun para el deber "posmoderno". Es en este sentido que puede plantearse que la moral y el deber como principios regulativos (principios moralizantes) constituyen realizaciones pedagógicas asociadas a determinadas bases colectivas de la sociedad. Como principios estructurantes se recontextualizan para influir en el amplio campo de la acción e interacción social, a la manera como los cambios en las bases sociales y, en consecuencia, sus límites han resemantizado las valoraciones del deber hacia nuevas lógicas centradas en el poder, la autorrealización, el deseo y el libre desarrollo de la personalidad, configurándose una nueva economía de la moral.

Es importante reconocer, entonces, que el concepto de pedagogía -en sus más diversas realizaciones - remite a la orientación de la acción e interacción del sujeto. Al ser portadora (o portavoz) de un amplio conjunto de principios, normas y valores, se la ha asociado con los contenidos prescriptivos del orden, relación, conducta, moral, autonomía, ética. Esto se ha constituido en un gran problema para su comprensión como medio, pues se la identifica ya sea

25 Originalmente publicado en 1748. 
con patrones o parámetros colectivos que se imponen sobre los individuos, ya sea con los contenidos que transmite. Por esta razón es posible encontrar apellidos que adjetivan modalidades pedagógicas. Así, por ejemplo, es común en las historiografías encontrar referencias a la pedagogía herbartiana, a la pedagogía kantiana, a la pedagogía roussoniana, o a la pedagogía piagetiana, y a muchas otras pedagogías, en las cuales cada autor encarna una determinada racionalidad pedagógica que termina convirtiéndose en una institución. Tenemos, entonces, que el reservorio metodológico de los múltiples autores que han hecho de su experiencia y de su ejercicio pedagógico "paradigmas del campo" son una fuente legitimante de lo que se ha denominado empíricamente saber pedagógico. Este puede considerarse en la historicidad un saber para la cotidianidad, común, que orienta o modela la vida. Pensemos por ejemplo en las obras pedagógicas de Locke, Kant, Hegel, Dilthey, etc. Podríamos decir que, de diferentes modos, todos estos autores recontextualizan la forma y contenido de un deber ser en un momento histórico y contribuyen a legitimar las múltiples realizaciones de la gramática pedagógica, todas ellas orientadas a crear límites estables del comportamiento y la identidad, que aún hoy son referentes básicos del denominado quehacer pedagógico.

Sin embargo, la consideración básica que sostenemos aquí es que la pedagogía no puede confundirse ni con los autores, ni con los contenidos que transmite. La pedagogía no es una entidad (no debe asociarse a una ontología) porque ante todo es un medio autónomo, un dispositivo que tiene sus propias dependencias internas. Ella está presente tanto en los procesos de disciplinarización y normalización como en los procesos de personalización, y se asocia a formas de control de los comportamientos, a la vez que participa de la configuración de creencias que van tejiendo los hilos de la cotidianidad y con ellos la configuración progresiva de las formas de conciencia. Por esta razón, indagar la pedagogía no es interrogar "contenidos temáticos, ni metodológicos" sino describir y explicar las lógicas de sus modalidades de intervención en el conocimiento, y en la producción de órdenes, y formas de relación e identidad específicas. Quizás muchos autores confunden la voz con los mensajes que la pedagogía transmite. El amplio sistema de mensajes enriquece las posibilidades regulativas de los sujetos y las instituciones. Sin embargo, a pesar de esto, su teleología común cambia en el tiempo y en el espacio y, en consecuencia, la forma y contenido de su voz y sus mensajes. Esa es la razón de ser del discurso pedagógico.

\section{Del discurso pedagógico}

En otro lugar hemos dicho que el discurso es un medio de constitución de identidad en los múltiples lugares donde produce orden y relación en el sujeto que constituye. Todo discurso lleva intrínsecos sus propios límites y, en estos, sus formas de cierre y apertura. Es esta tensión la que permite reproducir o transformar su poder constituyente, y definir campos, enfoques, perspectivas e, inclusive, disciplinas. En este sentido, el discurso pedagógico establece límites a los discursos y prácticas, y genera aperturas o cierres de conformidad con las voces e intereses que le subyacen. Esto es lo que permite la variación o el cambio pedagógico, articulado a la variación o al cambio social.

¿A qué llamamos discurso de la pedagogía? ¿Tiene la pedagogía un discurso propio? ¿Cuáles son los límites de su discurso y cuáles las limitaciones que ejerce sobre los discursos y prácticas? Estas preguntas nos plantean problemas cruciales que tienen que ver con la identidad de la pedagogía, su pretendida naturaleza disciplinaria y su rol en el posicionamiento en formas de conducta que se configuran en las relaciones sociales (Díaz y Muñoz, 1992). Estas últimas son, por lo general, unidimensionales y jerarquizadas, o abiertas, flexibles y autorregulativas, aunque tienen el poder y el control como sus principios regulativos.

Para comenzar, podría decirse que el discurso de la pedagogía o "discurso pedagógico" es un medio muy importante en la configuración del orden, relación e identidad dentro de y entre individuos y grupos sociales. Como discurso es una categoría que genera o produce significados que se realizan en la interacción social. Como medio es portador de dichos significados. Así, el discurso pedagógico es forma de comunicación sobre un contenido de comunicación. Aquí, es importante tener en cuenta que tanto la forma como el contenido de la comunicación varían de un contexto a otro. No es lo mismo, por ejemplo, el orden, la relación y la identidad que se constituyen en lo que denominamos contexto cultural primario (familia, comunidad, región) que el orden, relación e identidad que se constituye en la escuela. Si bien las formas de realización en cada contexto son específicas, lo que en adelante denominaremos gramática pedagógica se configura como un sistema de reglas, constante y unidireccional, independientemente de su realización contextual en la interacción social.

Por esto es importante distinguir entre el discurso pedagógico como una categoría plural constituida por una diversidad de discursos y objetos de estudio que apuestan a la existencia de un campo disciplinario, y 
el discurso pedagógico como una gramática constituyente de formas de conciencia y práctica intrínsecas a la legitimación de realidades cotidianas, epistémicas, o educativas, junto con sus principios y valores. En el segundo caso (como medio), el discurso pedagógico influye poderosamente en la configuración de certezas, representaciones, perspectivas, valoraciones, que producen el sentido de unidad de conciencia y entendimiento. Esto no niega el carácter discursivo de las prácticas pedagógicas, independientemente de los objetos sobre los cuales estas actúan. En la singularidad empírica de cada práctica pedagógica están establecidos los límites discursivos junto con sus voces y poderes intrínsecos. De este aspecto me ocupé en el artículo "De la práctica pedagógica al texto pedagógico" publicado en el número $1 \mathrm{de}$ Pedagogía y Saberes.

Así, podemos considerar el discurso pedagógico como el lugar desde donde se regula la experiencia y se genera experiencia regulada. Este punto de vista asume que el discurso pedagógico es intrínseco a los itinerarios discursivos del aprendizaje, desde los primeros estadios de la infancia, cuando se comienza la aculturación de los sentidos, y de las formas de comunicar y significar. Es de esta manera como se consolidan los comportamientos socioculturales genéricos que modelan expresiones colectivas e individuales en la vida, la educación y el trabajo.

Tenemos, entonces, que si ver, oír y tocar configuran los inicios de la semiosis individual, estos inicios pasan por el filtro del discurso pedagógico de quien hace ver, oír o tocar ${ }^{26}$. Esto significa la contextualización y recontextualización de la experiencia del otro, la autorización o desautorización del "yo", por otro yo legítimo, institucional y jerárquico. Este ha sido el itinerario de la pedagogía, asociado en la historia a la denominada formación del hombre o la constitución del yo singular. El primer término tiene una trayectoria bien definida: "su origen en la mística medieval, su pervivencia en la mística del barroco, su espiritualización, fundada religiosamente por el Mesías de Klopstock, que acoge toda una época"

26 Quizás podemos apostar aquí a la hipótesis según la cual la pedagogía es un medio de reproducción de teleologías, o que es en sí misma teleológica, a pesar de que cualquier racionalidad impuesta es extrínseca a la pedagogía. El "autorismo" (exceso de autores y autoridades pedagógicas históricas) generalmente conduce a confundir el medio con el mensaje que transmite. De allí la consideración esencialista y ontológica de la pedagogía por muchos autores y el privilegio de unos sobre otros.
(Gadamer, 1993, p. 38). El segundo, reproduce aún una tradición ontológica, esencialista, que hoy ha sido objeto de numerosos análisis críticos.

El discurso pedagógico ha sido fundamental tanto en la constitución de las visiones del mundo, la orientación de la voluntad, o la valoración de la vida, tanto en el sentido más clásico (Dilthey, 1994) como en lo que en el siglo Xxi se denomina de manera genérica "desarrollo de competencias". Aquí es importante tener en cuenta la diversidad de itinerarios experimentados en las ciencias sociales, en las cuales encontramos una gama de perspectivas doctrinarias que luchan por el posicionamiento simbólico $y$, por qué no decir, político alrededor de sus conceptos, métodos y procedimientos. Ellas con su diversidad de enfoques yuxtapuestos han contribuido a ampliar la gama de pedagogías del siglo XXI, con la producción de nuevos lenguajes y nuevas gramáticas descriptivas. Pensemos en la relación entre constructivismo y fenomenología o interaccionalismo, o entre constructivismo y neurociencia.

El discurso pedagógico, como medio, tiene la potencialidad de refuncionalizar, recontextualizar, o redefinir la razón, el hecho, la verdad, la conciencia, el lenguaje. Para el discurso pedagógico no hay espacio semántico impenetrable. Invade todo campo discursivo. Su inserción en el sentido genera otros sentidos que distorsionan el sentido primario. Por esto es posible decir que el discurso pedagógico es un discurso sobre otro discurso que produce un efecto de razón, de verdad, de conciencia, de mundo (Díaz Villa, 1979; 1980). Esto es lo que permite que la experiencia del sujeto sea reescrita, e inscrita en prácticas que al convertirse en dominantes legitiman y distribuyen identidades, posiciones y pertenencias, y mantienen sus sólidas o débiles diferencias. Por esta razón es que se puede argumentar que el discurso pedagógico es un discurso vaciado (vacío) de cualquier contenido, y que cualquier contenido - conocimiento, práctica, relación, visión, certeza, carácter, etc.- es susceptible de pedagogizarse, o realizarse como discurso pedagógico. Los efectos de verdad del discurso pedagógico radican en su fuerza modal, esto es, en el poder de convertir una noción, una opinión, en razón legítimamente constituida como verdad ${ }^{27}$.

27 Quizás debamos indagar el sincretismo alrededor del término poder. Por esto no es fácil establecer los límites semánticos entre el poder con el sentido de potencia, del poder con el sentido de autoridad. Sin embargo, es posible establecer la manera como en el desarrollo del niño, su poder (potencialidad intrínseca) es regulado por las relaciones de poder que se le imponen en las interacciones pedagógicas cotidianas. 
Tomemos como ejemplo el discurso religioso. Este es un dispositivo cuasi pedagógico que transforma la lógica de la creencia en "verdad lógica" (alétheia fabricada). Desde esta perspectiva, creencia y razón se sincretizan, y el espacio habitado por la creencia se convierte en "lugar de razón". A esto se agregan las posiciones de poder institucional incorporadas en las agencias de control y sus agentes reproductores capaces de configurar y reconfigurar formas de vida, interacciones, conductas, hábitos y prácticas como perfiles de subjetividad. El ser se realiza, entonces, como "ser en y de la familia", "ser en y de la escuela", "ser en y para un determinado tipo de sociedad", "ser en y para el trabajo", y así en todos los escenarios en los cuales se realiza la existencia. Como plantea Daly (2004, p. 12) refiriéndose a Žižek "el énfasis se pone en una noción del ser múltiple que siempre está configurado de forma provisional en planos resbaladizos de la différance"28.

Hoy, la semántica pedagógica ha adquirido un nuevo sentido como consecuencia de las transformaciones en las bases sociales del conocimiento y del surgimiento de la denominada economía del conocimiento. Por una parte, se exalta el advenimiento de la economía del conocimiento (knowledge economy o knowledge based-economy) (Carnoy, 2000; Olssen y Peters, 2005), o de la sociedad del conocimiento (learning society). Por la otra, se exhorta a una formación con un amplio sentido genérico y procedimental, vinculado a una performatividad referida al "proceso continuo de aprendizaje de conocimientos, habilidades, y de interiorización de pautas comportamentales" (Brunet y Belzunegui, 2003).

Esto es un indicador de los cambios en la voz del discurso pedagógico, voz que legitima nuevas formas de pedagogización y, particularmente, una mayor acción del Estado en la provisión de las agencias, agentes y discursos que recontextualizan las políticas, estrategias y modalidades educativas, dentro de una pluralidad de opciones, alternativas y tipologías, que responden a las demandas crecientes de flexibilidad y competitividad en todos los ámbitos de la vida y el trabajo. Esto ha tenido un impacto muy fuerte en las prácticas pedagógicas formales e informales.

La potencia individual cede frente a la omnipotencia de otro (el padre o la madre). Un interesante estudio al respecto está desarrollado en Rocheblave-Spenlé (1975).

28 En este sentido, Daly (2004) agrega que "la idea de sujeto ya no está de moda, puesto que supuestamente evoca la imagen de una identidad cartesiana unificada o cierta especie de centro de la subjetividad" (p. 12).
Estas últimas se han multiplicado, se formulan en lenguajes novedosos y, dados sus alcances, aparecen como democráticas, pregoneras de la autonomía y la autorrealización, y transformadoras de la identidad. Pensemos en el discurso de las competencias ${ }^{29}$. Examinemos ahora el asunto de la interacción social.

\section{Pedagogía e interacción social}

La interacción social, sus límites y los controles intrínsecos a estos son parte de los aspectos sobre los que versará esta sección. La reflexión que se presenta aquí implica la descripción y análisis de espacios (físicos y simbólicos), donde es posible reconocer y desconocer al otro, establecer diferencias y distancias con este e imponer, a través de diferentes formas de comunicación, cargas semánticas al sentido, la posición y la disposición ${ }^{30}$.

Estudiar la pedagogía es estudiar las relaciones estrechas que se dan entre el poder y el control en la interacción social, ya se refiera aquella a contextos socializantes compuestos de un transmisor (genérico o específico) y un aprendiz, o a otras formas de interacción desigual, como las que se dan entre médico y paciente, padres e hijos, patrón y trabajador, empleador y empleado. Todas estas relaciones, que paradigmáticamente son desiguales están reguladas por principios de poder y control. Al mismo tiempo, podemos decir que la fuerza de los límites que se establecen en la relación entre las categorías anteriores se expresa tanto en la estructura del poder, como en las modalidades de control que se dan entre ellas.

En todo contexto pedagógico podemos establecer dos tipos de categorías que crean la división del trabajo. El transmisor (y sus equivalentes físicos o virtuales, por ejemplo, los media), y el aprendiz (y sus equivalentes). Ambos ocupan una posición en la división del trabajo de la transmisión cultural.

29 Al respecto puede consultarse mi artículo titulado "El discurso de la flexibilidad y las competencias", en la revista Pedagogía y Saberes, 35 .

30 Hoy, esta última tiende a ser objeto, tanto en la escuela como en los contextos que podemos definir como cuasi pedagógicos (TIC), de la paradigmatización de códigos, que regulan los discursos y prácticas instruccionales y regulativas para producir y reproducir formas de conducta, relación e identidad genéricas, propias de las más variadas expresiones de los imaginarios del mercado, y del mercado de los imaginarios individuales y colectivos. Piénsese, por ejemplo, en todo el mercado de los imaginarios del cuidado, la salud, la nutrición, que circulan en las redes sociales como nuevas religiones terapéuticas. 
La interacción entre estas categorías depende de la naturaleza de los límites físicos y simbólicos que se establecen entre ellas. Es evidente que los límites en muchos casos son simbólicos e indeterminados por su porosidad. Por lo tanto, no son físicamente visibles. Si varía la forma de ser de los límites, las relaciones de poder entre las categorías pueden variar el contexto de interacción y la voz y el mensaje del controlador. Así, la forma de la interacción entre el maestro y el alumno, o entre el padre y el hijo es una consecuencia de la forma de ser de los límites entre estas categorías y de las posiciones que resultan de ellas. ¿Qué sucede, entonces, cuando entramos en relación con la lógica de las nuevas tecnologías de la información y la comunicación? ¿Cuál es la fuerza de los límites en esta relación? ¿Cómo afecta la identidad y la conciencia del socializante y del socializado? ¿Qué diferencia hay entre los límites que crea la división del trabajo y los límites en la interacción social? ¿Qué principios comunicativos se derivan de la existencia de límites rígidos en oposición a límites flexibles? ¿Cómo se reproduce el poder y el control en uno u otro caso? Si hoy asistimos al surgimiento amplio de "pedagogías flexibles" "autorregulativas", "seductoras", "virtuales" e inclusive "críticas", ¿qué nuevas relaciones de poder y control reproducen, interrumpen o transforman estas? El siguiente esquema nos permite, de manera descriptiva, establecer la diferencia de límites tanto en las distribuciones, agrupamientos o estratificaciones que produce la división del trabajo, así como los límites de la interacción social.

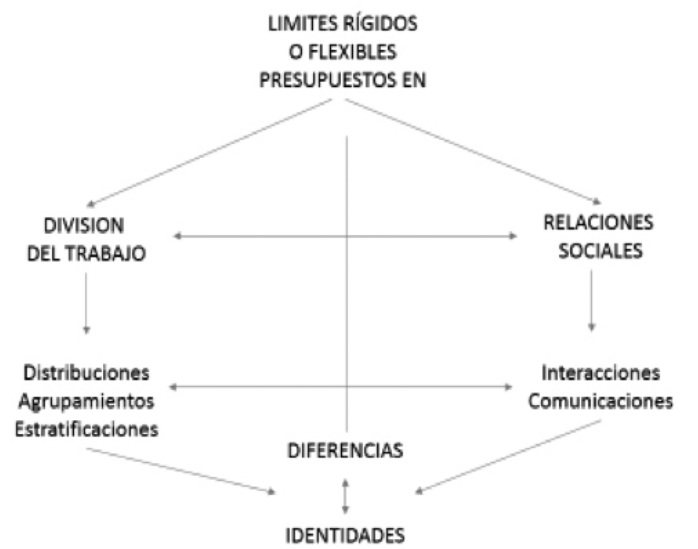

Figura 1.

Fuente: elaboración propia.

El esquema construye un marco descriptivo general (semiótico) de lo que podríamos denominar gramática de los límites susceptible de ser realizada en una amplia gama de contextos. Aquí, el discurso pedagógico regula posiciones y disposiciones, las cuales dependen de la rigidez o flexibilidad de los límites. A su vez, las diversas posiciones que reproduce la división del trabajo son una realización de las relaciones de poder que activan los límites.

Un tema crucial para el análisis, de acuerdo con el esquema, es el que tiene que ver con las relaciones sociales (interacciones, comunicaciones). Aquí debemos ocuparnos de manera general del concepto genérico de "práctica pedagógica". En toda práctica pedagógica están explícita o implícitamente presentes la división del trabajo (distribución del poder) y las relaciones sociales (principios de control). Toda práctica pedagógica tiene como referente básico los límites, esto es, al trazo fronterizo que separa dos espacios o, mejor, dos ámbitos a partir de los cuales se interactúa. Por esta razón, comprender la existencia de límites permite comprender su fuerza en la separación o aislamiento que estos producen y sus valores internos y externos. El problema básico que se plantea al referirnos a los límites es el de la diferencia. Se podría decir que los límites son constitutivos de la diferencia y de la pertenencia. Todo límite comporta diferencias. Luhmann (1998) plantea, por ejemplo, que

los sistemas se constituyen y se mantienen mediante la creación y la conservación de la diferencia [...] y utilizan sus límites para reglar dicha diferencia [...] en este sentido, la conservación de los límites (boundary maintenance) es la conservación del sistema. (p. 40).

Luhmann agrega que los límites pueden entenderse como dispositivos especiales para la función de separar. Una de las funciones que los límites desempeñan es la de separación, mediante la cual los sistemas pueden abrirse o cerrarse. En este sentido, la determinación de los límites es el requisito más importante en la diferenciación de los sistemas (Luhmann, 1998, pp. 50-52). Podríamos decir, entonces, que los sistemas tienen límites, que la experiencia está regulada por límites, que hay límites en la interacción, que un orden social se fundamenta en la internalización de unos límites (trazos) que se convierten en principios regulativos de la acción e interacción. Por esta razón, las realizaciones morales pueden constituir toda una expresión semiótica de las configuraciones de los límites espacio-temporales, que el sujeto internaliza.

Los límites (fronteras) llevan intrínsecos los temas de la inclusión y la exclusión. También implican el problema de la identidad. "Una frontera es la 
línea donde una cosa termina y otra comienza... una frontera tiene que ver tanto con identificar como con excluir" (Borradori, 2003, p. 207).

Cada vez que nos referimos a la interacción social presuponemos no solo la existencia de límites, sino también la existencia de formas de control que están explícitas o implícitas en las formas de interacción. Un asunto de interés es pensar cómo los límites de la interacción social han variado en el tiempo, y cómo dichas variaciones han generado nuevas formas de comunicación/significación y nuevas modalidades pedagógicas de control. Quizás esto nos permita comprender por qué las formas de interacción hoy se han desritualizado y ya no se expresan en los términos jerárquicos y verticales de tiempos pasados. Otra manera de comprender este asunto es remitirse a lo que ocurre con la globalización, con la cual se han derribado o suplantado las fronteras geográficas y culturales por una especie de reespacialización a partir del desarrollo vertiginoso de las tecnologías de la comunicación e información, con las cuales se pretende elevar la identidad al rango de genérica (identidades genéricas).

Lo que se quiere decir cuando se habla de debilitamiento de los límites es que el fundamento contenido en las prácticas de interacción actuales se asocia a la flexibilidad, a la deconstrucción, al debilitamiento de las posiciones jerárquicas, al descentramiento de los marcos limitados y limitantes de la comunicación. Así, en la relación pedagógica se producen nuevas modalidades de control simbólico que tienen un efecto profundo en la modelación de la socioafectividad, en la realización de las expectativas, en el comportamiento de los individuos y, de manera específica, en su identidad.

En síntesis, el tema de la interacción —pedagógica- es un tema de límites y, en consecuencia, de poderes y controles. En este sentido la transmisión cultural tiene intrínsecamente el tema de los límites, implica la comprensión de las relaciones entre pedagogía y control. Esto significa que no podemos reflexionar el asunto de la pedagogía si dejamos de lado el asunto de los límites y el asunto del control. Desde este punto de vista, interpretar la pedagogía es interpretar los límites y las limitaciones. Aquí debemos introducir una digresión que puede conducir a examinar la flexibilización de los límites como la deslegitimación de las limitaciones o, mejor, a considerarla como simple deslimitación asociada a formas de resistencia o contestación. Pero este es un tema que desborda los límites de este artículo. En otro artículo abordaremos este asunto con más especificidad.

\section{Pedagogía, poder, control y comunicación}

En la sección anterior se planteó cómo en la medida en que el poder y el control son inseparables de la consideración de los límites físicos y simbólicos, y son estructurantes de la forma y contextos de interacción, regulan la experiencia de los individuos y grupos, así como los significados que circulan entre ellos. La naturaleza de los límites, hemos dicho, genera las posibilidades y el espacio potencial para las posiciones, oposiciones y estrategias de poder y control. En este sentido, los límites son el punto crítico para la definición del conocimiento, de la práctica y de las experiencias significantes de toda interacción pedagógica.

Podríamos afirmar que sin una descripción de los límites no podríamos entender cómo operan el poder y el control, ni tampoco cómo se constituyen en (o viajan a) la conciencia. Por esto, reiteramos que el estudio de los límites nos proporciona las herramientas intelectuales para examinar el poder, el control, la rigidez o flexibilidad en la interacción (rigidez o flexibilidad pedagógica) y, en consecuencia, las nuevas formas de ser, estar y hacer de individuos y grupos.

Son numerosos los interrogantes que surgen cuando nos planteamos las relaciones entre pedagogía, poder y control. Entre otros: ¿qué reproduce o transforma la pedagogía? ¿Cuál es su papel en la distribución inequitativa del poder y del control? ¿Cómo reproduce la inequidad de dicha distribución? ¿Afecta una modalidad pedagógica la reproducción de principios de comunicación dominantes? Estos interrogantes nos remiten al problema de los límites que genera una u otra modalidad pedagógica, y su relación con el poder, el control y viceversa.

Examinemos brevemente el problema del poder. El poder presupone la existencia de posiciones que crean la división del trabajo. La división del trabajo atribuye a los sujetos una determinada posición que se expresa en términos de poder, saber, ser o actuar. Cada posición se configura sobre la base de distribuciones desiguales, y de los límites que se establecen entre ellas. De allí que haya una diferencia crucial entre una "posición dominante" y una "posición dominada". Una posición dominante configura identidad al poder, garantiza su hacer, su acción, o sus actos. En el sentido spinoziano que le atribuye Deleuze, la concepción de poder no es solo un principio de acción, sino que también es un principio de afección. Esto implica una producción y una sensibilidad, equivalente, en la perspectiva de Bourdieu, a la relación 
intrínseca entre "posición" y "disposición"31. De lo que denominamos relaciones de poder surgen las tensiones, oposiciones o conflictos entre las posiciones y conlleva sus disposiciones pertinentes.

Examinemos ahora con mayor detenimiento el asunto del control. Este - hemos dicho- está asociado a los límites que se crean en las relaciones sociales, en la interacción social o, de manera redundante, en los contextos de interacción. El control "regula y justifica la comunicación en las relaciones pedagógicas: el carácter de la expresión hablada y los tipos de espacios construidos", plantea Bernstein (1998). El control tiene que ver con los límites de la comunicación (comunicación pedagógica): quién controla qué. En este sentido, el control afecta la lógica de la comunicación o, dicho de otra manera, la forma y el contenido de la comunicación. Aquí nos encontramos con el hecho que el control también tiene que ver con los límites - ahora, de la comunicación-. De hecho, estos límites afectan no solo la estructura de un contexto de interacción sino también lo que se dice y cómo se dice.

Si afirmamos que a mayor fuerza de los límites mayor la distribución desigual de espacios (externos e internos) y mayor la desigualdad en la distribución de posiciones, discursos y prácticas de interacción, podemos inferir que, a menor fuerza de los límites, mayor flexibilidad. Esta conclusión es parcial porque no describe qué ocurre con el poder y el control. El asunto, de mucho interés, obliga a preguntarnos qué significado tiene el mantenimiento de determinados límites en la relación pedagógica o la producción de nuevas formas límites. ¿Se transforman (debilitan) las relaciones de poder? ¿Se transforman (debilitan) los principios de control? 0 acaso, ¿se reproducen de otra manera? He allí el problema. ¿Por qué problema? Porque el debilitamiento de los límites - casi que su

31 En su libro sobre Deleuze, Michael Hardt considera que en Spinoza el poder tiene dos lados que son siempre iguales e indivisibles: el poder de afectar y el poder de ser afectado, producción y sensibilidad. Según Hardt, Spinoza distingue en "el poder de ser afectado" afecciones activas (aquellas causadas internamente) y afecciones pasivas (aquellas causadas externamente). No es fácil abordar esta distinción filosófica en el campo sociológico, a no ser por las inferencias relacionadas con las tensiones entre lo interno y lo externo al sujeto, y en lo interno, las tensiones entre la capacidad de acción de un sujeto en una posición de poder, y las disposiciones, que en última instancia surgen de dicha posición, las cuales pueden expresarse en principios morales, éticos, políticos, y en la perspectiva que se adopte en las prácticas del sujeto. Este asunto es importante para la comprensión de la manera como se expresa el poder en la relación entre categorías como, por ejemplo, padre-hijo, maestro-alumno, médico-paciente, o sus equivalentes. Véase Hardt (2005). deconstrucción - ha entrado en el juego de las deslegitimaciones al convertir casi que en legítima cualquier acción individual o colectiva que excluye, descalifica, intimida. Pero también, el debilitamiento de los controles externos paradójicamente ha facilitado el fortalecimiento de los controles sobre lo interno, permitiendo visibilizar las diversas expresiones de los aspectos más íntimos del ser. Esto nos permite decir que estamos en las puertas de las paradojas del control, paradojas que hacen posible un mayor ejercicio del poder.

\section{Conclusión}

Tal como se dijo en la introducción, el propósito básico del artículo ha sido desarrollar un enfoque sobre la pedagogía desde una perspectiva sociológica, o preferiblemente desde una sociología de la pedagogía. Esta postura pareciera ser una adición a la innumerable lista de perspectivas y aproximaciones que se han impuesto y convertido en dominantes en el campo de la pedagogía. Pero no. Como hemos dicho en otro lugar, el metodologismo pedagógico poco se ha interesado en analizar la estructura interna de la pedagogía, sus reglas intrínsecas, sus modalidades y las consecuencias de estas. De allí la necesidad de ir más allá de las descripciones que solo se concentran en los aspectos visibles o empíricos de la pedagogía, susceptibles de ser observados y de develar sus reglas subyacentes que constituyen una gramática que podemos considerar fundamental para leer el poder y el control intrínseco a prácticas pedagógicas existentes, y escribir prácticas pedagógicas capaces de deconstruirlos. Quizás esta tarea se inscriba, de otra manera, en las denominadas pedagogías de la resistencia.

Frente al instrumentalismo metodológico imperante que adapta, reproduce, o recontextualiza y genera propuestas empíricas aparentemente novedosas, se requiere ampliar el campo de investigación crítica sobre la pedagogía (diferente de una pedagogía crítica) que aborde el estudio de la dispersión y variedad de la amplia producción de textos que reiteran lugares comunes sobre la pedagogía y recontextualizan la pluralidad de enfoques de las ciencias sociales, a la manera de "todo vale" en la era del textualismo y la discursividad.

El artículo es igualmente una crítica para quien participa cotidianamente en los procesos de formación (modelación, socialización primaria o secundaria - escolar-). En el campo pedagógico es común la falta de comprensión de la existencia de un orden 
subyacente que regula la diversidad de sus acciones e interacciones pedagógicas, o de la diferencia entre gramática pedagógica y sus realizaciones prácticas y, mucho menos, de la expresión gramática pedagógica. Gran parte de la literatura pedagógica se mueve entre la adhesión a la formalidad de las rutinas pedagógicas y de sus enfoques que las fundamenta y las describe espontáneamente, con métodos como el etnográfico ${ }^{32}$, por ejemplo, o toma como referentes los modelos fijados institucional u oficialmente. Podemos agregar que, para nuestros propósitos analíticos, este artículo puede considerarse la reapertura del debate sobre las diversas comprensiones sobre el discurso y la práctica pedagógica.

Trascender la estructura social en la cual se está inmerso, y de la cual los investigadores de la pedagogía debieran ser permanentes observadores y analistas, puede ser una necesaria tarea del hoy denominado campo de la pedagogía ${ }^{33}$. En este caso, el pedagogo debiera diferenciarse - hablando metafóricamente- del personaje cotidiano que diariamente habla para comunicar/significar pero que no es consciente de las reglas que configuran su discurso (Díaz, 1990).

\section{Referencias}

Bachelard, G. (1973). La formación del espíritu científico. México: Siglo XXI.

Bernstein, B. (1998). Pedagogía, control simbólico e identidad. Madrid: Morata.

Bernstein, B. (2001). From pedagogies to knowledge. En A. Morais, I. Neves, B. Davies y H. Daniels (eds.), Towards a sociology of pedagogy. The contribution of Basil Bernstein to research. Nueva York: Peter Lang.

Borradori, G. (2003). La filosofía en una época de terror: diálogos con Jürgen Habermasy Jacques Derrida. Bogotá: Aguilar.

32 Este método fue ampliamente difundido y utilizado en Colombia durante la década de los ochenta, a partir de la influencia de Elsie Rockwell, quien se refirió a la perspectiva etnográfica y no al método etnográfico. Su influencia fue determinante en las investigaciones de Rodrigo Parra Sandoval, Aracelly de Tezanos de Mañana, Leonor Zubieta y de otros investigadores pertenecientes al entonces Centro de Investigaciones de la Universidad Pedagógica. Un desarrollo de esta perspectiva la realiza Díaz (1992) en su libro El campo intelectual de la educación en Colombia.

33 Es importante aclarar que para el autor no hay horizontalidad entre campo (intelectual) de la educación y campo de la pedagogía. Este punto será aclarado en una próxima publicación.
Brunet, I. y Belzunegui, A. (2003). Flexibilidad y formación: una crítica sociológica al discurso de las competencias. Barcelona: Icaria.

Carnoy, M. (2000). Sustaining the new economy. Cambridge: Harvard University Press.

Cassirer, E. (s. f.). La tragedia de la cultura. elaleph.com. Recuperado de http://coral.ufsm.br/gpforma/2senafe/ PDF/b30.pdf

Cassirer, E. (1951). Las ciencias de la cultura. México: Fondo de Cultura Económica.

Cassirer, E. (1972). La filosofía de la ilustración. México: Fondo de Cultura Económica.

Cortina, A. (1995). Ética sin moral. Madrid: Tecnos.

Daly, G. (2004). Slavoj Žižek, arriesgar lo imposible. Conversaciones con Glyn Daly. Madrid: Trotta.

Díaz, M. (1979). Hacia una crítica de la pedagogía. Revista Universidad del Valle, 2.

Díaz, M. (1980). Sobre la pedagogía. Revista Universidad del Valle, 7.

Díaz, M. (1990). De la práctica pedagógica al texto pedagógico. Revista Pedagogía y Saberes, 1, 14-27.

Díaz, M. y Muñoz, J. (1992). Pedagogía discurso y poder. Bogotá: Corprodic.

Dilthey, W. (1988). Teorías de las concepciones del mundo. Madrid: Alianza.

Dilthey, G. (1944). Introducción a las ciencias del espíritu. México: Fondo de Cultura Económica.

Foucault, M. (2004). Nietzsche, la genealogía, la historia. Valencia: Pre-Textos.

Foucault, M. (1970). El orden de discurso. México: Tusquets.

Gadamer, H. (1993). Verdad y método. Salamanca: Sígueme.

Geiger, T. J. (1930). Programa e introducción a una sociología de la educación. Revista de la Asociación de Sociología de la Educación (RASE), 1(1), 74-79.

Hardt, M. (2005). Gilles Deleuze: un aprendizaje filosófico. Buenos Aires: Paidós.

Horkheimer, M. (2007). Crítica de la razón instrumental. Argentina: Terramar.

Hume, D. (1990). Investigaciones sobre el conocimiento humano. Madrid: Alianza.

Jaeger, W. (2004). Paideia. México: Fondo de Cultura Económica. (Primera edición en español, 1945). 
Knorr Cetina, K. y Bruegger, U. (2000). The market as an object of attachment: Exploring postsocial relations in financial markets. Canadian Journal of Sociology, 25(2), 141-168.

Lash, S. (2005). Crítica de la información. Buenos Aires: Amorrortu.

Lipovetsky, G. (2002). La era del vacío. Ensayos sobre el individualismo contemporáneo. Barcelona: Anagrama.

Lipovetsky, G. (2008). El crepúsculo del deber. La ética indolora de los nuevos tiempos democráticos. Barcelona: Anagrama.

Luhmann, N. (1998). Sistemas sociales: lineamientos para una teoría general. Barcelona: Anthropos.
Lyotard, F. (1987). La condición postmoderna: informe sobre el saber. Madrid: Cátedra.

Mouffe, C. (1994). La democracia radical ¿moderna o postmoderna? Revista Leviatán, 55.

Olssen, M. y Peters, M. A. (2005). Neoliberalism, higher education and the knowledge economy: from the free market to knowledge capitalism. Journal of Education Policy, 20 (3), 313-345.

Rifkin, J. (2000). La era del acceso. La revolución de la nueva economía. Buenos Aires: Paidós.

Rocheblave-Spenlé, A. (1975). El poder desenmascarado. Madrid: Sociedad de Educación Atenas.

Vignaux, P. (1954). El pensamiento en la Edad Media. México: Fondo de Cultura Económica. 